\title{
ANAESTHESIA FOR CEREBRAL ANGIOGRAPHY: CARDIOVASCULAR AND CEREBROSPINAL FLUID PRESSURE OBSERVATIONS IN THE MONKEY UNDER PENTOBARBITAL-HALOTHANE ANAESTHESIA
}

\author{
J. W. R. MCINTYRE, F.F.A.R.C.S., J. D. R. MLLER, M.B., CH.B., F.R.C.P.(C), \\ AND B. K. A. WEIR, M.D., M.SC., F.R.C.s. (C)
}

A AECENT STUDY of simulated subarachnoid haemorrhage in monkeys afforded an opportunity to observe some of the effects of cerebral angiography performed under these experimental conditions.

\section{Experimental Procedure}

The monkeys were female rhesus weighing between 2.6 and $6.9 \mathrm{~kg}$. They were sedated with sodium pentobarbital administered intraperitonealy 35 to 75 (median 55) $\mathrm{mg} / \mathrm{kg}$ body weight approximately three hours prior to angiography. In 7 out of 26 experiments this was supplemented by the intravenous injection of 4 to $10 \mathrm{mg} / \mathrm{kg}$ some 60 minutes prior to angiography. Intubation of the trachea with a flexometallic tube was carried out under direct vision. Tubocurarine $0.2 \mathrm{mg} / \mathrm{kg}$ was administered intravenously and artificial ventilation was begun. A Harvard variable volume ventilator and its associated animal ventilation graph (Kleinman and Radford) was used for this purpose. The predicted stroke volume necessary for maintenance of a $\mathrm{PcO}_{2}$ within normal limits was trebled, and carbon dioxide was added to the inspired vapour. The gases supplied to the reservoir for the ventilator passed through flowmeters and a Fluotec halothane vaporizer. They consisted of $4 \mathrm{~L} / \mathrm{min}$ of oxygen and carbon dioxide. The "Fluotec" dial setting was 0.75 . Once artificial ventilation had begun, the system remained unaltered for the duration of the experiment. Thirty minutes were allowed, following the start of artificial ventilation, for stabilization prior to angiography.

\section{Measurements}

Cerebrospinal fluid (CSF) pressure was monitored from a catheter in the region of L-3 using a Statham Transducer and an Electronics for Medicine Amplifier. Carotid arterial pressure was monitored using identical equipment. Cardiac rhythm was monitored from lead 2 using an Electronics for Medicine Amplifier. Permanent records were made on an Electronics for Medicine PR-7 Recorder. Oesophageal temperature was measured with a Yellow Springs thermometer. The Astrup micro technique was used to measure blood gases, this being done within an hour of sampling from the carotid artery.

-Departments of Anaesthesia, Radiology, and Neurosurgery, Surgical Medical Research Institute, University of Alberta, Edmonton, Alberta. Supported in part by M.R.C. Grant no. 2835 . 


\section{ANGIOGRAPHY}

A \#6 French radio-opaque polyethylene catheter (RAPOL, USCI) with curved tip, $88 \mathrm{~cm}$ long, lubricated with sterile silicone (Dow Corning 555) was inserted through a femoral arteriotomy. Under fluoroscopic control the catheter tip was manipulated into the distal innominate artery and a test dose of $2 \mathrm{ml}$ Megumine Iothalamate (Conray 60) used to confirm its position. The animal was placed on an Elema Schonander biphasic roll film changer with the chin flexed. Megumine Iothalamate $8 \mathrm{ml}$ was injected by a Cordis I injector at $400 \mathrm{psi}$, and biphasic films were obtained at a rate of 4 per second for 1.5 seconds, 2 per second for 2.0 seconds, and 1 per second for 2 seconds.

\section{Technique for Simulated Subarachnom Haemorrhage}

A few days before the experiments a twist drill hole was made in the animal's skull. When required, a needle could then be inserted under X-ray control so that its tip would lie in the cranial basal subarachnoid space and injections could be made through it.

\section{RESULTS}

lization period, classified according to the arterial $\mathrm{PCO}_{2}$ at that time, and designated

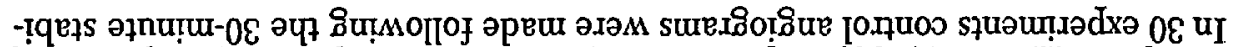
hypercarbic (more than $44 \mathrm{~mm} \mathrm{Hg}$ ) normocarbic (36-44 $\mathrm{mm} \mathrm{Hg}$ inclusive), or hypocarbic (less than $36 \mathrm{~mm} \mathrm{Hg}$ ). The hypercarbic animals had an arterial $\mathrm{pH}$ in the range of 7.26 to 7.42 (median 7.35). Two of these showed a base and bicarbonate deficit. No such deficits occurred in the normocarbic group in which $\mathrm{pH}$ varied from 7.36 to 7.44 (median 7.38 ). The hypocarbic animals, three in number, were hypothermic and had a metabolic acidosis. The oesophageal temperatures of the animals at the time of the control angiograms varied from 30.5 to $37.25^{\circ} \mathrm{C}$, with a median of $34.2^{\circ} \mathrm{C}$.

The blood pressure and pulse rate changes associated with the injection of contrast media are summarized in Table I. A slight reduction in pulse rate occurred in the thirteen cases. A reduction in systemic blood pressure was recorded in every case, varying from 10 to $54 \%$ (median $26 \%$ ). The control values had been regained in ten minutes by ten of the twenty-nine animals.

The basal cSF pressure prior to injection of contrast media varied considerably from 54 to $190 \mathrm{~mm}$ of water (median $95 \mathrm{~mm}$ ). A transient increase of 14 to $40 \mathrm{~mm}$ occurred during the positive pressure phase of each respiratory cycle. Changes in pressure occurred following the injection of contrast media, and two or three minutes had often elapsed before control values were regained. The increase in pressure was 14 to $40 \mathrm{~mm}$ of water (median $14 \mathrm{~mm}$ ).

Changes in cardiac rhythm were infrequent. Twenty-four subjects had a normal rhythm before and after injection. In two others, preinjection ventricular extrasystoles persisted unchanged following injection of contrast media. In four other cases inverted $\mathbf{P}$ waves persisted following injection and in a fifth case the inverted $P$ wave reverted to normal. 
MCINTYRE \& MILLER: ANAESTHESIA FOR CEREBRAL ANGIOGRAYHY

TABLE I

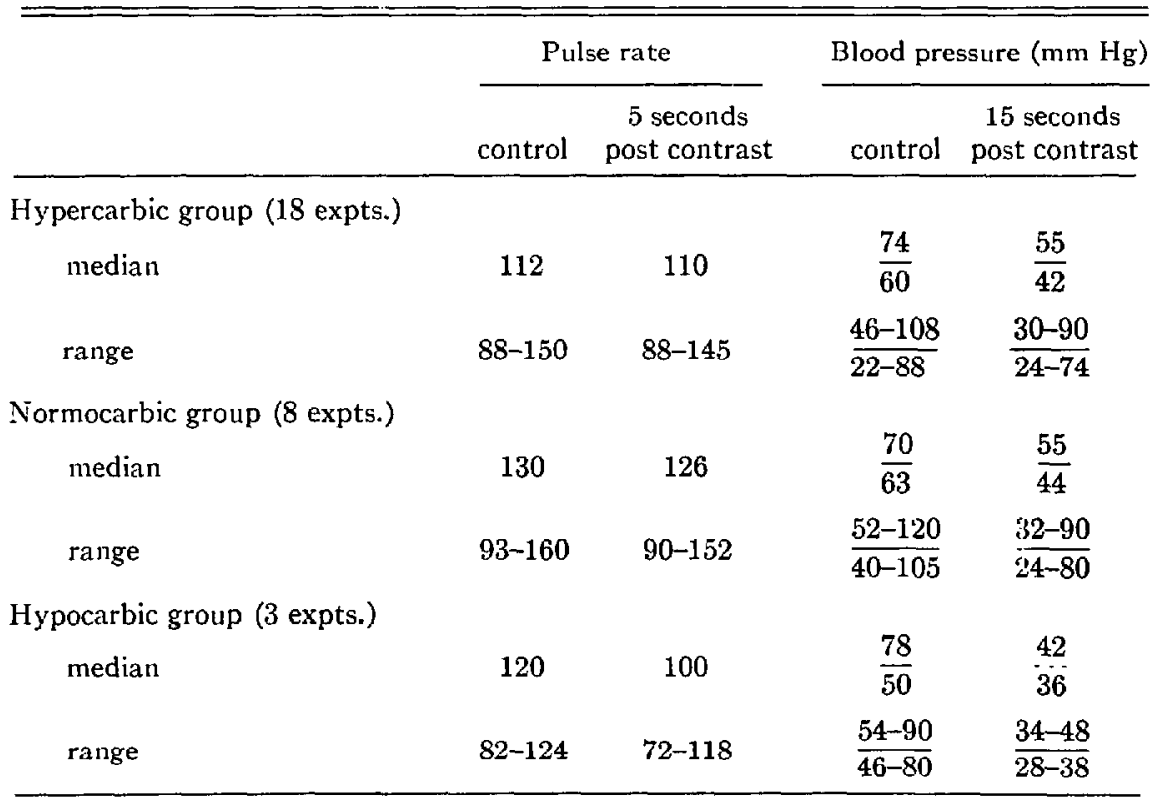

The remaining angiograms were carried out from one to forty minutes following the experimental subarachnoid injection of blood, and at the time they were performed the resulting disturbance in intracranial dynamics had not always stabilized. In addition, in some instances inspired carbon dioxide tension had been increased for periods of 10 to 15 minutes. The temperature of the animals at this time varied from 29.8 to $37^{\circ} \mathrm{C}$, with a median of $33.3^{\circ} \mathrm{C}$. The precontrast blood pressures had a range of $40 / 20$ - 112/100 (median 68/56). The pressures recorded 15 seconds after the injection of contrast medium had a range of $30 / 22-88 / 80$ (median $52 / 40$ ). These changes can be represented by a reduction in a range of 2 to $40 \mathrm{~mm} \mathrm{Hg}$ (median $17 \mathrm{~mm} \mathrm{Hg}$ ) in the mean systemic blood pressure.

The CSF pressure changes are variable. Sometimes a brief elevation similar to that described for the control contrast injections occurred, but in every instance in which the control cSF pressure was $272 \mathrm{~mm} \mathrm{H}_{2} \mathrm{O}$ or more this increase was not demonstrated. In a few instances the diastolic blood pressure and CSF pressure were almost coincident. These findings are summarized in Table II.

Alterations in cardiac rhythm were infrequent. In 48 instances it was normal before and after injection of the contrast medium. In four other instances the $\mathbf{P}$ wave was inverted prior to injection and remained unchanged except in one case when normal rhythm was restored. The five other cases multifocal ventricular extrasystoles were occurring prior to injection. In three cases this remained unchanged and in two cases normal rhythm developed.

Arterial blood samples taken prior to and two to three minutes following the injection of the contrast medium in 15 cases showed changes summarized in Table III. 
TABLE II

\begin{tabular}{lcc}
\hline $\begin{array}{c}\text { Post-contrast diastolic } \\
\text { blood pressure }(\mathrm{mm} \mathrm{Hg})\end{array}$ & $\begin{array}{c}\text { Simultaneous post-contrast } \\
\text { csf pressure }(\mathrm{mm} \mathrm{Hg})\end{array}$ \\
\hline 1 & 32 & $32 / 25$ \\
2 & 44 & $48 / 40$ \\
3 & 34 & $36 / 32$ \\
4 & 70 & $70 / 58$ \\
5 & 48 & $58 / 48$ \\
6 & 52 & $51 / 36$ \\
\hline
\end{tabular}

TABLF. III

\begin{tabular}{ll}
\hline $\mathrm{pH}$ & Range of change $0-0.12$ (median 0.03 ) in 14 out of 15 experiments \\
$\mathrm{PCO}_{2}$ & Range of change $+8.0 /-7.0 \mathrm{~mm} \mathrm{Hg}$ in 15 experiments (median +0.5 ) \\
$\mathrm{PO}_{2}$ & Range of change $+30 /-30 \mathrm{~mm} \mathrm{Hg} \mathrm{in} 15$ experiments (median +15 ) \\
$\mathrm{HCO}_{3}$ & Range of change $0 /-4.9$ (median 1.7$) \mathrm{mEq} / \mathrm{L}$ \\
$\mathrm{Base}$ & Range of change $0 /-5.9$ (median 1.9$) \mathrm{mEq} / \mathrm{L}$ \\
\hline
\end{tabular}

\section{Discussion}

The manner in which cerebral angiography is performed and the means to make it tolerable for the patient must ensure the minimum undesirable alterations in the patient's physiological state. Many of the possible changes interact with one another and have in common a potential for permanent damage to cerebral cells. They include alterations in cardiac rate and rhythm, blood pressure, cardiac output, intracranial pressure, acid-base balance, and the blood brain barrier. Individually and collectively these changes, as well as the EEG, have been used in the assessment of the toxicity of contrast media. ${ }^{1-3}$

Contrast media alter vascular permeability and diffuse into surrounding tissue. The effects of different preparations vary widely and have been discussed by Harrington. ${ }^{4}$ The factors involved are protein binding, contact time, differences in permeability of the sodium and methyl glucamine salts of the diatrizaoate compound, and penetration of sodium ions into the cells. To these could be added pathological changes already existing in the blood brain barrier and alterations in its behaviour that may be produced by the presence of anaesthetic drugs and by hyperventilation. ${ }^{\overline{0}}$

The clinical occurrence of biphasic blood pressure responses to cerebral angiography has been previously described. ${ }^{6}$ In 1966 Hilal, ${ }^{7}$ using dogs, experimentally related biphasic changes to alterations in heart rate. Each of these alterations was a reduction in systemic blood pressure, the first being related to stimulation of receptors in the common carotid artery and the second to a direct effect of the contrast medium on the brain. The stimulation of intracarotid receptors has been implicated in the production of bradycardia and hypotensive responses by other workers in the clinical and laboratory situation., ${ }^{3,6,8-10}$ In the series reported here there did not appear to be a clearly defined biphasic blood pressure response, and such slowing of the heart rate as did occur was small. However, a more serious bradycardia may have occurred during the period of seconds between injection and recording. The occasions on which sinus domi- 
nance was regained at least temporarily following contrast injection are believed to be associated with the resulting reduction in blood pressure or vagal stimulation restoring sinus dominance, mechanisms described by Dresel. ${ }^{11}$ The hypotensive responses were assumed to be a combination of central and reflex effects of the contrast injection as well as of peripheral vasodilatation. The acid-base changes were consistent with the injection of an acid substance, and similar to those expressed by Marshall. ${ }^{12}$

The development of a prolonged rise in cerebrospinal fluid pressure following experimental angiography has been described by previous workers. ${ }^{13,14}$ Clinical studies $^{15}$ have demonstrated only a transient rise for less than 30 seconds, particularly in patients who were in coma or under general anaesthesia. The results reported here are in keeping with these previous reports. Their significance is in their relationship to the diastolic blood pressure existing at the time. The relationship of blood pressure and CSF pressure to adequate cerebral blood flow is widely recognized, and attention has previously been drawn to changes in these parameters under halothane anaesthesia. ${ }^{16-18}$ The observations presented here clearly demonstrate the necessity for the blood pressure to be maintained at a level that will provide adequate cerebral oxygenation in the presence of an increased or increasing intracranial pressure.

The characteristics of the technique of ventilation employed during neuroradiological procedures are of particular interest at the present time..$^{19-24}$ Some anaesthetists and radiologists favour passive hyperventilation, believing that visualization of cerebral vessels is improved, though caution has been expressed regarding the use of the technique in patients with known or suspected intracranial cardiovascular pathology. Perfusion of cerebral cells is as important as visualization of vessels and the recent observations of Soloway ${ }^{95}$ are relevant to this discussion. As far as the work presented here is concerned, the effects of contrast injection on blood pressure, cardiac rhythm, and cerebrospinal fluid pressure were similar whether the animals were hypercarbic or normocarbic. However, the possibility that contrast injection produces a greater blood pressure fall in hypocarbic animals cannot be ruled out. It is noteworthy that the animals in the present series which developed a diastolic pressure similar to the cerebrospinal fluid pressure had a $\mathrm{PCO}_{2}$ range of $40.5-56.5$ (median 50.0 ) $\mathrm{mm} \mathrm{Hg}$, and a temperature range of $30^{\circ}-35^{\circ} \mathrm{C}$ (median 33.5).

Anaesthesia for angiography has been reviewed by Gilbert ${ }^{26}$ and Michenfelder. ${ }^{27}$ The data reported here principally supplement information already available. However, they clearly indicate the variations in cardiovascular and cerebrospinal fluid pressure changes that can occur under approximately standard conditions and the unpredictability of changes which may occur in each individual situation. Naturally, outside the experimental environment and in a clinical setting, anaesthesia and angiography would be suitably modified as the situation demanded. However, the requirements for these modifications and the efficacy of the modifications that are made can be known only if suitable parameters are monitored during the procedure. It is clear that this is particularly necessary in patients with suspected or known increase in intracranial pressure.

Forty-five angiograms performed subsequently under similar conditions have produced effects similar to those described. 


\section{SUMMARY}

Cerebral angiography performed under pentobarbital-halothane anaesthesia on normal Rhesus monkeys and those undergoing experimental subarachnoid haemorrhage afforded an opportunity to study the effects of angiography on cardiac rhythm, systemic blood pressure, and cerebrospinal pressure. Meglumine Iothalamate was the contrast medium employed, and the animals varied considerably in temperature, $\mathrm{PCO}_{2}$, and $\mathrm{pH}$. ECG changes were infrequent and minor. Varying degrees of hypotension occurred, and on a few occasions the diastolic blood pressure following the injection of contrast was similar to the CSF pressure. These events and the apparently unpredictable responses to angiography under pentobarbital halothane anaesthesia indicate the necessity for monitoring relevant parameters in subjects with suspected or known increase in cerebrospinal fluid pressure.

\section{RÉSUMÉ}

L'angiographie cérébrale pratiquée sous anesthésie au pentothal-fluothane chez des singes Rhésus normaux et chez ceux qui subissaient une hémorragie sous-arachnoïdienne expérimentale a fourni l'opportunité d'étudier les effets de l'angiographique sur le rythme cardiaque, sur la pression sanguine systémique et sur la pression cérébro-spinale. Comme substance opaque on a utilisé l'Iothalamate de Méglumine et les animaux ont varié beacoup quant à la température, la $\mathrm{PCO}_{2}$ et le $\mathrm{pH}$. L'ECG n'a subi que des variations rares et peu importantes. A des degrés variables, il s'est produit de l'hypotension et à quelques occasions la pression sanguine diastolique consécutive à l'injection de substance opaque était semblable à la pression du liquide céphalo-rachidien. Ces constatations et les réponses apparemment imprévisibles à l'angiographie sous anesthésie au pentothal-fluothane montrent la nécessité de moniteurs pour les paramètres qui se rapportent d cette intervention, chez les sujets chez qui l'on soupçonne une hypertension du liquide cérébro-spinal ou qui réellement souffrent de cette hypertension.

\section{ACKNOWLeDgments}

Grateful thanks are expressed to D. Secord, D.v.M., I. D. M. Miller, M.D., F.R.C.P.(C), D. Dobson, M.B., B.CH., and R. Erasmo, M.D., who assisted in this work. Mallinkrodt Pharmaceuticals, St. Louis kindly donated supplies of Conray 60. Canadian Kodak Company kindly donated supplies of Kodachrome Royal Blue film.

\section{REFERENCES}

1. Fischen, Harry W. Viscosity, Solubility, and Toxicity in the Choice of an Angiographic Contrast Medium. Angiology. 16: 759 (1965).

2. Bloor, Byron M.; Wrenn, Frank R.; \& Hayes, George J. An Experimental Method for the Evaluation of Contrast Media Used in Cerebral Angiography. J. Neurosurg. 8: 435 ( 1951$)$.

3. Lundervold, Arne \& Engeset, Afne. Polygraphic Recordings of EEG, ECG and Blood Pressure during Cerebral Angiography with Isopaque B. Acta Radiol. (Diagn.) Suppl. 270: $87(1967)$. 
4. Harrington, G.; Michie, C.; Lynch, P. R.; Russell, M. A.; \& Oppenheimer, M. J. Blood Brain Barrier Changes Associated with Unilateral Cerebral Angiography. Invest. Radiol. 1: 431 (1966).

5. Rengachert, Setti S.; Roth, David A.; Andrew, Norman W.; \& Mark, Vernon H. Alteration of the Blood Brain Barrier with Hypoventilation. J. Neurosurg. 26: 614 (1967).

6. Brown, A. S. Circulatory Disturbances during Angiography. Anaesthesia. 10: 346 (1955).

7. HrLaL, SADEK K. Hemodynamic Changes Associated with the Injection of Contrast Media. Radiol. 86: 615 (1966).

8. Brindle, G. Fred; Gilbert, R. G. B.; \& McGrath, Jorn J. Cardiovascular and Respiratory Observations during Cerebral Angiography. Anesth. \& Analg. 44: 565 (1965).

9. Greitz, Torgny \& Tornell, Gunnar. Bradycardia during Cerebral Angiography. Acta Radiol. (Diagn.) Suppl. 270: 75 (1967).

10. Zsebox, Z. B. Von \& SzLAvy, L. On the Effects of Angiographic Contrast Media on the Cardiovascular and Respiratory System. Fortschr. Roentgenstr. 105: 406 (1966).

11. Dresel, Peter E. \& Sutter, Morley C. Factors Modifying Cyclopropane Epinephrine Arrhythmias. Circ. Res. 9: 1284 (1961).

12. Marshill, M. \& Henderson, S. A. Tendency to Acidosis Following the Injection of Radio Opaque Contrast Material. Brit. J. Radiol. 41: 190 (1968).

13. Bassett, Robert L.; Rogers, James S.; Cherry, Glenn R.; Gruzhit, Carl. The Effect of Contrast Media on the Blood Brain Barrier. J. Neurosurg. 10: 38 (1953).

14. Kagstrom, Erik \& Lindgren, Percy. Changes in Intracranial Pressure during Carotid Angiography. Acta Radiol. 54: 379 (1960).

15. Wricht, R. Lewis \& Wilkinson, Harold A. Cerebrospinal Fluid Pressure Recordings during Carotid Angiography in Man. Neurochinurgia. 8: 97 (1965).

16. Chrustensen, M. Stig.; Hoedt-Rasmussen, K. \& Lassen, N. A. Cerebral Vasodilatation by Halothane Anaesthesia in Man and Its Potentiation by Hypotension and Hypercapnoea. Brit. J. Anaesth. 39: 927 (1967).

17. Barker, J.; Eitch, W.; Jennetr, W. B.; \& McDowall, D. G. Anaesthesia for Cerebral Angiography. Brit. J. Anaesth. 40: 307 (1968).

18. Lewis, R. N. \& Moore, B. A. Some Aspects of General Anaesthesia for Cerebral Angiography. Brit. J. Anaesth. 40: 37 (1968).

19. Zaclis, José; Lonco, Pedro H.; \& Cruz, Oswaldo Ricciardi. Intrathoracic Hyperpressure in Neuroradiology Results in: 1) Cerebral Panangiography and 2) Arteriography of the Thoraco-cervical Region. J. Neurosurg. 21: 1087 (1964).

20. Rockoff, S. David; Doppman, John; Kreugen, Thomas P.; Thomas, Lewis J.; \& OMMAYa, AxuB. Altered Opacification of the External Carotid Circulation by Changes of Enexpiratory Carbon Dioxide Tension: An Angiographic Study in Man. Invest. Radiol. 1: 123 (1966).

21. Amundsen, A. K.; Amundsen, P.; \& Refsum, H. Circulation Time and Pattern in Cerebral Angiography Using Different Techniques for General Anaesthesia. Acta Radiol. (Diagn.) 5: 84 (1966).

22. Hawkins, T. D. The Influence of Carbon Dioxide Tensions on the Angiographic Appearance of Intracranial Tumours. Brit. J. Radiol. 41: 804 (1968).

23. Ferris, Ernest J; Orlando, Gabriele F.; Hipona, Florencia A.; \& Shapiro, Jerome H. Early Venous Filling in Cranial Angiography. Radiology. 90: 553 (1968).

24. Samuex, John R.; Grange, Rosemary A.; \& Hawkins, Desmond T. Anaesthetic Technique for Carotid Angiography. Anaesthesia. 23: 543 (1968).

25. Soloway, Mark; Nadel, William; Albin, Maurice; \& White, Robert J. The Effect of Hyperventilation on Subsequent Cerebral Infarction. Anesthesiology. 29: 975 (1968).

26. Gilbert, R. S.; Brindle, G. Fred; \& Galindo, Anibal. Investigations and Diagnostic Procedures. Int. Anesth. Clin. 4: 767 (1966).

27. Michenfelder, John D.; Gronert, Geraid A.; \& Remder, KaI. Neuroanesthesia. Anesthesiology. 30:65 (1969). 